\title{
Pediatric Diabetes Insipidus
}

\author{
Irina Suley Tirado Pérez ${ }^{1 *}$ and Andrea Carolina Zárate Vergara ${ }^{2}$ \\ ${ }^{1}$ Medical Epidemiologist, Master Pediatric Palliative Care, University of Santander, Colombia \\ ${ }^{2}$ Medical Epidemiologist, Graduate Student Pediatric Intensive Care, University of Santander, Colombia
}

*Corresponding author: Irina Suley Tirado Pérez, Medical Epidemiologist, Master Pediatric Palliative Care, Graduate Student Pediatric Intensive Care, University of Santander, Colombia

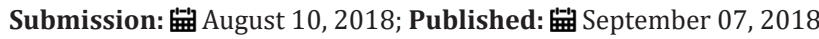

\begin{abstract}
Diabetes insipidus is a rare condition, with classic signs of clinical presentation and are polyuria and polydipsia, presented by excessive fluid intake, absence or resistance to the action of antidiuretic hormone, below is a topic review will be made explaining the pathophysiological characteristics of this disease, its diagnosis and treatment.
\end{abstract}

Keywords: Diabetes insipidus; Polyuria; Polydipsia; Vasopressin

\section{Introduction}

Mainly diabetes insipidus is characterized by clinical symptoms such as polyuria and polydipsia, secondary to absolute or relative lack of secretion or action of antidiuretic hormone (ADH), also called vasopressin, three presentations, primary polydipsia when much ingests liquid, which suppresses ADH, the other presentations is called central diabetes insipidus when there is deficiency of this hormone, as nephrogenic diabetes insipidus is due to a resistance to the action of vasopressin, these entities may arise from hereditary defects or other causes [1,2].

Its cause is usually due to destruction or degeneration of neurons originate in the supraoptic and paraventricular nuclei. Other causes include inflammatory and local autoimmune diseases, vascular diseases, intracranial tumors, trauma or brain malformations, histiocytosis Langerhans, sarcoidosis, other genetic causes, is genetic defects in the synthesis of arginine vasopressin (AVP) inherited as autosomal dominant, autosomal recessive, or $\mathrm{X}$-linked recessive traits, nephrogenic diabetes insipidus secondary to mutations in the AVP receiver recept V2 (AVPR2), resulting in a loss of function or dysregulation of AVPR2 renal, also described as causal abnormalities aquaporin 2 (AQP2) water channel gene $[3,4]$.

\section{Definitions}

\section{Dipsogénica diabetes insipidus or primary polydipsia}

Primary polydipsia occurs because the amount of liquid ingested by the patient is much higher than the requirement hypersensitivity center thirst, thereby decreasing the osmolality of the internal environment, causing a suppression of secretion of $\mathrm{ADH}$, thus giving the clinical feature is polyuria, occurs in patients with psychiatric, anxious or diseases drugs such as phenothiazines $[1,5,6]$.

\section{Central diabetes insipidus}

Central diabetes insipidus caused by deficiency of arginine vasopressin, also called cranial diabetes insipidus or hypothalamic, may have a sporadic or familial behavior, central diabetes insipidus sporadic may be due to causes that alter the hypothalamus or hypothalamohypophysial area, as craniopharyngioma, may present clinically isolated or associated with deficits of anterior pituitary hormones; central diabetes insipidus family is presented by mutations in the coding for ADH, which is located chromosome 20 p13 in with an autosomal dominant pattern of inheritance, clinical presentation may be from infancy to adult $[3,5]$. In a retrospective study, conducted in Peru in pediatric population was observed that the most common cause of central diabetes insipidus intracranial tumors were at $55.7 \%$, then of Langerhans Cell Histiocytosis with $13.9 \%$ and malformations brain with $8.9 \%$ and $17.7 \%$ idiopathic causes $[7,8]$.

\section{Nephrogenic diabetes insipidus}

Nephrogenic diabetes insipidus is rare, it is presented by the inability to concentrate urine, although their antidiuretic hormone, occurs most X-linked, recessively frequency, and is seen in disorder affecting renal tubular function, either urologic obstructive disease, renal failure, renal cystic disease, interstitial nephritis, among others, and can be sporadic and family. Sporadic mainly occurs by hyperglycemia, which causes osmotic diuresis, inverting the gradient across the renal tubule, diabetes insipidus family is linked 
to the X chromosome, specifically there alteration in Xq28, and its most severe clinical presentation it occurs during lactation $[5,9,10]$.

\section{Epidemiology}

Diabetes insipidus is a rare entity, it is estimated in the literature that has a prevalence of 1 per 25000 inhabitants, being most often central diabetes insipidus, which nephrogenic diabetes insipidus, with a smaller percentage etiology of hereditary nature less than $10 \%$; diabetes insipidus in the raw X-linked, reporting 4 to 8 cases per million live births $[3,11]$.

\section{Pathophysiology}

Water homeostasis is balanced by release of the antidiuretic hormone vasopressin and stimulation of the thirst. Vasopressin is produced in the magnocellular neurons of the paraventricular and supraoptic nuclei of the hypothalamus that send axons to the posterior pituitary nuclei, which is responsible for segregating arginine vasopressin into the bloodstream where it acts in the kidney duct renal collecting increasing the reabsorption water duct renal collecting (eleven).

Vasopressin is secreted response fluid volume changes, acting as principal regulator of water permeability in the renal collecting ducts, aquaporin are essential water permeability of the apical membranes mainly AQP2, in the absence of signaling AVP, no such permeability When binding AVP receptor V2 AVPR2 exists, a signaling cascade ultimately leading starts insertion AQP2 channels in the apical membrane AVPR2, this binding leads to the release of stimulatory $\mathrm{G}$ protein being a receptor bound to this protein, which in turn activates adenylyl cyclase and simultaneously increases the levels of cAMP activates protein kinase a (PQA), there mediated phosphorylation of $\mathrm{AQP2} \mathrm{PQA}$, stimulation of AQP2 potentiates allowing water permeability and water reabsorption in the collecting system [12-14].

The release and synthesis of AVP is primarily regulated by plasma osmolality gap or eletrolitros as sodium, while the latter increase produces a significantly stimulate release and transcription AVP gene, When there is a deficiency of AVP, known as central diabetes insipidus, leading to hypotonic polyuria, when there is resistance arginine vasopressin renal distal tubule, leading to a deficiency in tubular reabsorption of water occurs nephrogenic diabetes insipidus $[8,13]$

\section{Diagnosis}

Diagnosis requires a complete medical history and physical examination, the main symptoms are polyuria and polydipsia, many children have decreased weight excluding the fluid, or in children greater intellectual involvement by pictures of repetitive dehydration, these episodes of dehydration when severe can lead to seizures. It can also present vomiting, constipation, fever, irritability, sleep disorders, growth retardation and stunting, when having visual impairment should be thought of brain tumors or associated symptoms with other diseases such as septo-optic dysplasia consisting defects midline, nystagmus, hypoglycemia, jaundice and micropenis $[15,16]$.

Known as polyuria urine production 24 hours, with a fluid intake than $2 \mathrm{l} / \mathrm{m} 2 / 24 \mathrm{~h}$ or about $150 \mathrm{~mL} / \mathrm{kg} / 24 \mathrm{hr}$ at birth, $100-$ $110 \mathrm{~mL} / \mathrm{kg} / 24 \mathrm{~h}$ up to the age of 2 years and $40-50 \mathrm{~mL} / \mathrm{kg} / 24 \mathrm{~h}$ in older children and adults, should apply eletrolitos serum as potassium, calcium, glucose and creatinine for differential diagnosis, is also very useful measure urine osmolality $<300 \mathrm{mOsm} /$ $\mathrm{kg}$ and $0 \mathrm{sm}>300 \mathrm{mOsm} / \mathrm{kg}$ serum think diabetes insipidus, while discarded if urine $0 \mathrm{sm}>600 \mathrm{mOsm} / \mathrm{kg}$, or serum $0 \mathrm{sm}<270 \mathrm{mOsm} /$ $\mathrm{kg}$, and if there symptomatology should be performed deprivation test water $[2,16]$.

Images are requirement to assess the etiology of diabetes insipidus, especially MRI to look for brain tumors, this posterior pituitary can be seen as a hyperintense on sagittal T1 images, the lack of this in the posterior pituitary can mean disorders and identify at an early age of local tumors hidden $[3,17]$.

\section{Treatment}

The main objective of management for diabetes insipidus is decreased urine output and thirst control, allowing adequate control of levels of sodium and water homeostasis, the management of primary forms of diabetes insipidus focuses on dietary modification to reduce the salt load. In central diabetes insipidus the fluid therapy plays an important role in newborns and infants require large volumes $(3 \mathrm{~L} / \mathrm{m} 2 / 24 \mathrm{~h})$, accompanied by analogue of vasopressin as desmopressin have a good result and prevents complications, is in various presentations as oral, intranasal, or subcutaneous preparation, oral is preferred over intranasal, and on subcutaneous for ease in administration, oral dose is from 0.025 to $1.2 \mathrm{mg}$ /day in $1-3$ doses, $5-10 \mathrm{mcg}$ intranasal, $0.1-0.2 \mathrm{mcg}$ subcutaneous or continuous infusion to vasopressin $3.1 \mathrm{mU} / \mathrm{kg} / \mathrm{hr}$, in an intensive care unit $[2,8,11]$.

\section{References}

1. Cheetham T, Baylis PH (2002) Diabetes insipidus in children: pathophysiology, diagnosis and management. Paediatr Drugs 4(12): 785-796.

2. Majzoub DTB, Josh A (2012) Diabetes insipidus. In: Nelson Treaty of Pediatrics, pp. 1954-1956.

3. Di Iorgi N, Napoli F, Allegri AEM, Olivieri I, Bertelli E, et al. (2012) Diabetes insipidus-diagnosis and management. Horm Res Paediatr 77(2): 69-84.

4. Abu-Libdeh A, Wexler ID, Dweikat I, Zangen D, Abu-Libdeh B (2017) A novel mutation in the AVPR2 gene in a family with nephrogenic diabetes palestinian insipidus. JCS 1(1): E1-E3.

5. Garcia Garcia E (2011) Diabetes insipidus concept. Protoc Asoc Spanish Pediatrics 1(1): 44-53.

6. Diabetes insipidus F (2002) Laczi: etiology, diagnosis, and therapy. ORV Hetil 143(46): 2579-2585.

7. De Los Santos MA, Aguila CM, Red MI, Falen JM, Nunez O, et al. (2016) Central diabetes insipidus: clinical profile suggests that organicity in Peruvian children: Lima -Peru 2001-2013. J Pediatr Endocrinol Metab 29(12): 1353-1358. 
8. Arima H, Azuma Y, Morishita D (2016) Hagiwara central diabetes it is insipidus. Nagoya J Med Sci 78(4): 349-358.

9. Avner SR (2012) Nephrogenic diabetes insipidus. In: Nelson Treaty of Pediatrics, pp. 1882-1883.

10. Böckenhauer D, Bichet DG (2017) Nephrogenic diabetes insipidus. Curr Opin Pediatr 29(2): 199-205.

11. Dabrowski E, Kadakia R (2016) Diabetes insipidus D. Zimmerman in infants and children. Best Pract Endocrinol Metab Res Clin 30(2): 317328.

12. Böckenhauer D, Bichet DG (2015) Pathophysiology, diagnosis and management of nephrogenic diabetes insipidus. Nat Rev Nephrol 11(10): 576-588
13. Schernthaner MH-Reiter, Stratakis CA, Luger A (2017) Genetics of diabetes insipidus. Endocrinol Metab Clin North Am 46(2): 305-334.

14. Lu Haj (2017) Diabetes Insipidus BT -Aquaporins. In: Yang B (Ed.), Dordrecht: Springer, Netherlands, Europe, pp. 213-225.

15. Kochhar RS (2017) Diabetes insipidus S Ball. Medicine (Baltimore) 45(8): 488-491.

16. Jain V, Aathira R (2016) Diabetes insipidus in children. Journal of Pediatric Endocrinology and Metabolism 29: 39.

17. Di Iorgi N, Morana G, Napoli F, Allegri AEM, Rossi A, et al. (2015) Management of insipidus and adipsia in the child diabetes. Best Pract Endocrinol Metab Res Clin 29(3): 415-436.

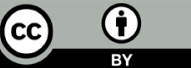

Creative Commons Attribution 4.0 International License

For possible submissions Click Here
Submit Article

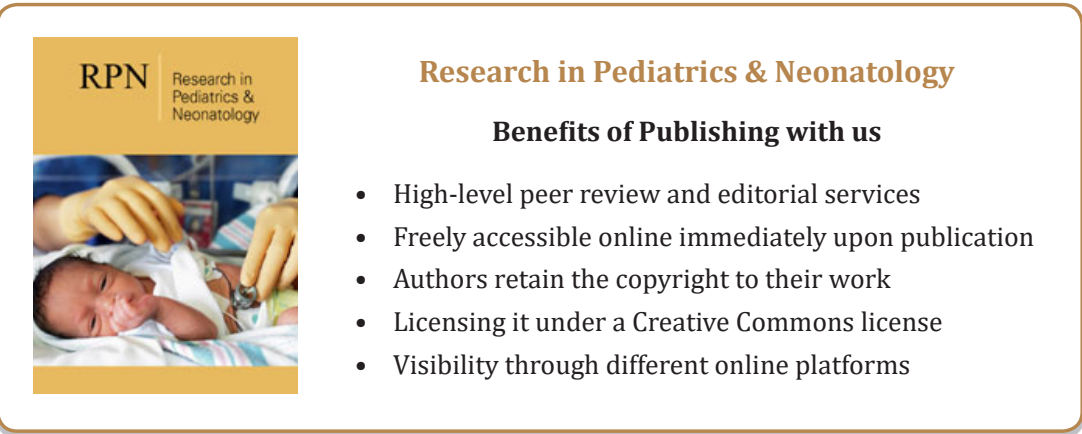

